\title{
Flower Position and Size Impact Ovule Number per Flower, Fruitset, and Fruit Size in Pomegranate
}

\author{
Hazel Y. Wetzstein ${ }^{1}$, Weiguang Yi, and Justin A. Porter \\ University of Georgia, Department of Horticulture, 1111 Miller Plant Science Building, Athens, \\ GA 30602 \\ Nadav Ravid \\ Paramount Farming Company, 33141 E. Lerdo Highway, Bakersfield, CA 93308
}

\begin{abstract}
AdDitional INDEX words. Punica granatum, flower vigor, fruit quality
Abstract. Pomegranate trees (Punica granatum) produce large numbers of both hermaphroditic (bisexual) flowers that produce fruit and functionally male flowers that characteristically abort. Excessive production of male flowers can result in decreased yields resulting from their inability to set fruit. Within hermaphroditic flowers, sex expression appears to follow a spectrum ranging from those exhibiting strong to weak pistil development. Unknown is the scope that flower quality plays in influencing fruit production. A description of floral characteristics and how they vary with flowers of different sizes and positions is lacking in pomegranate and was the focus of this study. Furthermore, the effects of flower size and position on fruit set and fruit size were evaluated. This study documents that flower size characteristics and ovule development can be quite variable and are related to flower type and position. Single and terminal flowers within a cluster were larger than lateral flowers. In addition, lateral flowers exhibited a high frequency of flowers with poor ovule development sufficient to negatively impact fruiting in that flower type. Ovule numbers per flower were significantly influenced by flower size with more ovules in larger flowers. Pollination studies verified significantly higher fruit set and fruit weight, and larger commercial size distributions were obtained with larger vs. smaller flowers. Thus, flower quality is an important issue in pomegranate. Cultural and environmental factors that influence flower size and vigor may have a direct consequence on fruit production and yield.
\end{abstract}

Pomegranate has been grown as a fruit crop since ancient times. Pomegranate fruit are composed of an outer leathery pericarp that contains hundreds of juice-containing arils. It is marketed as whole fresh fruit, extracted arils, juice, syrups, teas, and as an ingredient in a wide range of products. Numerous recent studies have verified the many health benefits associated with pomegranates, which include efficacy against conditions including cancer, coronary heart disease, atherosclerosis, hypercholesterolemia, hypertension, HIV, infectious diseases, and aging (Basu and Penugonda, 2008; Holland et al., 2009; Lansky and Newman, 2007; Seeram et al., 2006). This has led to an increase in the production and consumption of fresh fruit, juice, and other pomegranate products.

The morphological and histological characterization of pomegranate flowers has been recently described (Wetzstein et al., 2011a). Both hermaphroditic (bisexual) and functionally male flowers are on the same plant, a condition referred to as andromonoecy. Although pomegranate flowers are commonly portrayed as falling within either bisexual or male floral types, sex expression appears to follow a spectrum where flowers can range from those with strong pistils to those with vestigial development (Holland et al., 2009; Wetzstein et al., 2011a). This indicates that flower quality is inconsistent, and that even within bisexual flower types, the strength and vigor of individual flowers are variable. This leads to the question of whether flower vigor and quality as expressed in differences in flower size and degree of female development influence fruit production in pomegranate.

Received for publication 12 Dec. 2012. Accepted for publication 14 Feb. 2013. We thank Erik Wilkins for assistance in the field and acknowledge Paramount Farming Company for field, research, and financial support.

${ }^{1}$ Corresponding author. E-mail: hywetz@uga.edu.
Flower and/or ovary size have been shown to impact final fruit size in a number of crops including peach [Prunus persica (Scorza et al., 1991)], rabbiteye blueberry [Vaccinium ashei (Johnson et al., 2011)], and olive [Oleo europaea (Rosati et al., 2009)]. Flower "strength" has been observed to affect fruitsetting ability in apple (Malus $\times$ domestica), which may encompass factors such as bud size, spur position, flower quality, and location (Dennis, 1986). With apple flowers that are typically produced in a cluster of five to six flowers, the terminal or king flower consistently sets more fruit than lateral flowers. Unclear are the relative contributions in this case of differences in flower size, time of development, and sink strength.

In a study characterizing attributes related to fruit size in pomegranate, fruit volume, fruit weight, total aril weight, and total number of arils per fruit were highly correlated (Wetzstein et al., 2011b). In contrast, individual aril weight had no significant relationship to fruit size, indicating that a better approach to optimize size in pomegranate is to increase the number of arils per fruit rather than to promote more extensive aril enlargement. Large fruit were found to contain upward of 1000 arils per fruit. Each aril is derived from a single ovule in which an independent fertilization event occurs. Thus, production of large fruit requires the fertilization of hundreds of ovules. Fruit size can be quite variable even among fruit harvested from the same orchard under similar management conditions. Unknown is the scope that flower quality plays in influencing fruit production. A description of floral characteristics and how they vary with flowers of different sizes and positions is lacking in pomegranate. Likewise, the number of ovules in flowers has not been previously reported. Is ovule number per flower a factor that limits aril number and thus fruit size? Flowering in pomegranate can be as single flowers or in 
flower clusters containing a more advanced terminal flower subtended frequently by two to four lateral flowers (Wetzstein et al., 2011a). Unclear are how flower types differ in size and morphology and whether terminal vs. lateral flowers have divergent fruiting capacity.

As part of an ongoing project on pomegranate reproductive biology, the present work aims to evaluate how bisexual flower quality characteristics influence fruit set and development. Factors evaluated include the morphological characterization of different flower types (i.e., single flowers, terminal flowers, and lateral flowers) to ascertain if flower vigor influences fruit production. Specifically, 1) floral characteristics were measured in populations of different flowers types and flower size distribution patterns determined; 2) the numbers of ovules in individual flowers were determined and related to flower size; and 3) hand pollination studies were conducted to determine if flower size subsequently influences fruit set and fruit size. These studies will provide information to determine if flower type and vigor impact fruit set and size in pomegranate. Establishing how flower quality affects fruiting can have important implications in crop production applications. Optimizing cultural conditions may be a means to promote the development of greater numbers of high-vigor bisexual flowers to obtain maximum fruit set and yield.

\section{Materials and Methods}

Plant material and Study location. Studies were conducted using 'Wonderful' pomegranate trees grown in a commercial orchard located near Delano, CA. Trees were managed under conventional methods. Flower development and pollination studies were conducted during the early-to-midseason flowering period. Flower position/size studies were conducted in May 2009; hand pollination/fruit size studies were conducted during the 2010 growing season.

Flower POSITION AND SIZE. Pomegranate flowers are borne either as single flowers (Fig. 1A) or in clusters of commonly one terminal, more advanced flower, subtended by one or two pairs of oppositely opposed flowers arranged in a decussate orientation (Fig. 1B-C). Three types of flowers were collected for evaluation: 1) single flowers (Fig. 1A); 2) terminal flowers within a flower cluster (Fig. 1C); and 3) lateral flowers within a flower cluster (Fig. 1D). One hundred bisexual, newly opened flowers of each type were collected from several trees within the same orchard block. Selection of bisexual flowers was based on the appearance of a visible stigma/style and urn-shaped ovary; male flowers were avoided, judged by the lack of a visible stigma/style and a bell-shaped ovary (Wetzstein et al., 2011a). Flowers were immediately taken back to the laboratory, individual flowers numbered, and measurements taken of the flower characteristics diagramed and numbered in Figure 2: 1) maximum ovary width; 2 ) length from the base of flowers to the sepal notch; 3) length from the base of flowers to the tip of sepals flattened for measurement; 4) total length of the pistil; 5 ) length of the stigma, style, and stylopodium; 6) length of the stigma and style; and 7) stigma diameter. The basal portion of flowers containing the ovary and ovules was dissected, placed into individually numbered vials, and fixed with HistoChoice fixative (Amresco, Solon, $\mathrm{OH}$ ) for later evaluations of ovule numbers.

Ovule number. Counts of ovule numbers were conducted for two flower types: single flowers and terminal flowers within
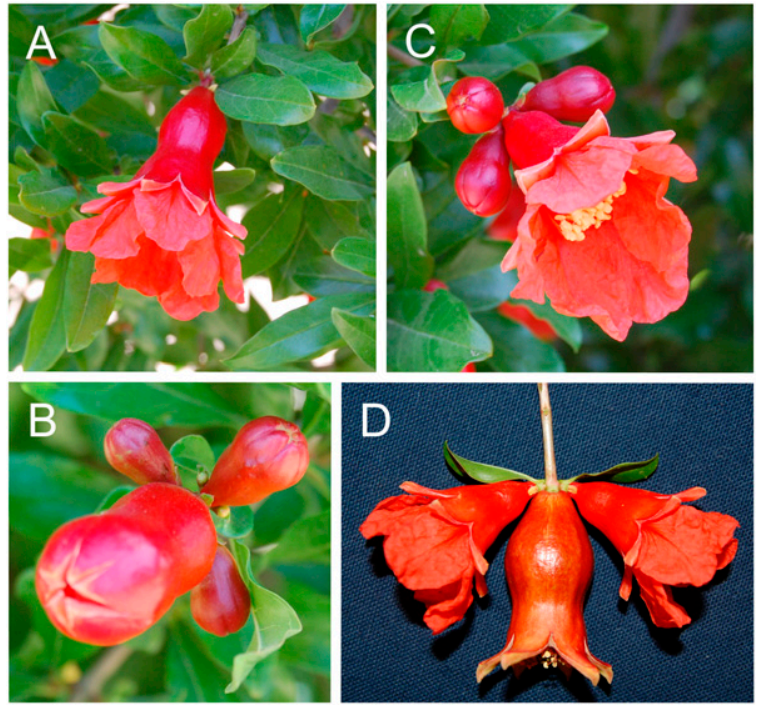

Fig. 1. Pomegranate flower types: (A) single flower. (B) Unopened buds showing flower cluster composed of a terminal flower bud subtended by two pairs of oppositely opposed flower buds arranged in a decussate orientation (one of the lateral buds is hidden from view). (C) The terminal flower in the flower cluster at the open petal stage. (D) Lateral flowers within a flower cluster have opened; the terminal flower is past bloom, petals have abscised, and the ovary has enlarged.
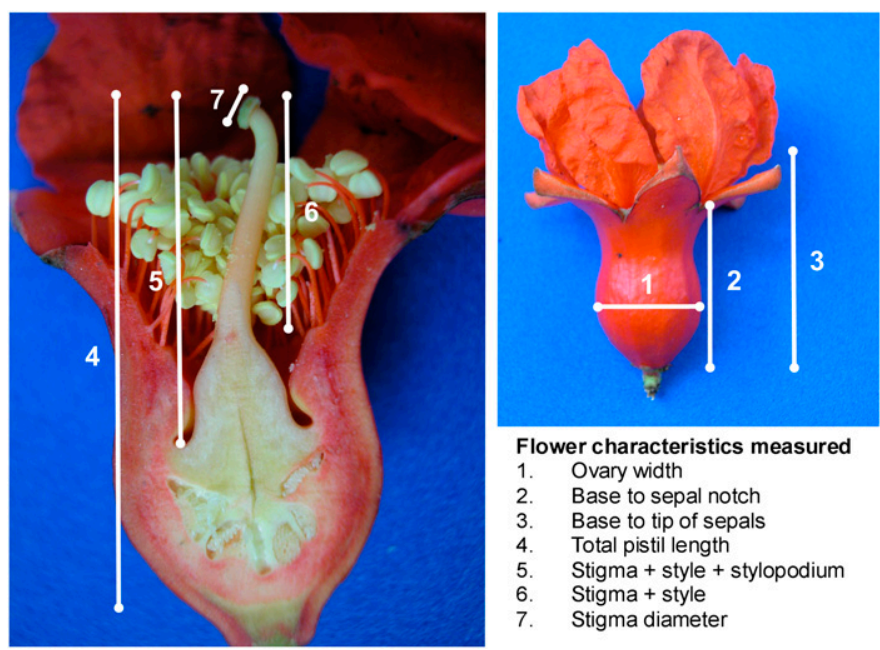

Fig. 2. Pomegranate flower characteristics measured: (1) maximum ovary width; (2) length from the base of flowers to the sepal notch; (3) length from the base of flowers to the tip of sepals when flattened for measurement; (4) total length of the pistil; (5) length of the stigma, style, and stylopodium; (6) length of the stigma and style; (7) stigma diameter.

a cluster. Flowers used were a subset of those measured for flower position and size studies. Ovaries from 53 flowers were carefully dissected under a dissecting microscope, and individual ovules were separated from placental and other ovarian tissue using fine probes. The hundreds to thousands of ovules obtained from each flower were collected and portioned out into several 12-well cell culture plates with 22.1-mm diameter wells (Costar, Cambridge, MA) (Fig. 3A). For each flower, ovules were plated into $\approx 36$ wells. Ovules were carefully distributed to avoid clumping of ovules in the wells, culture plates were placed on a light box, and each well 
was photographed (FinePix S2000 Digital Camera; Fujifilm, Tokyo, Japan) using super macro settings (Fig. 3B). An image analysis program, APS Assess (American Phytopathological Society, St. Paul, MN), was used to count the number of ovules (Fig. 3C). Each well image count was further manually verified to make count corrections as needed by adding undercounted touching ovules and/or subtracting miscounted cellular debris. Counts were not conducted on lateral flowers within a cluster as a result of the high numbers of flowers of that type containing degenerated ovules.

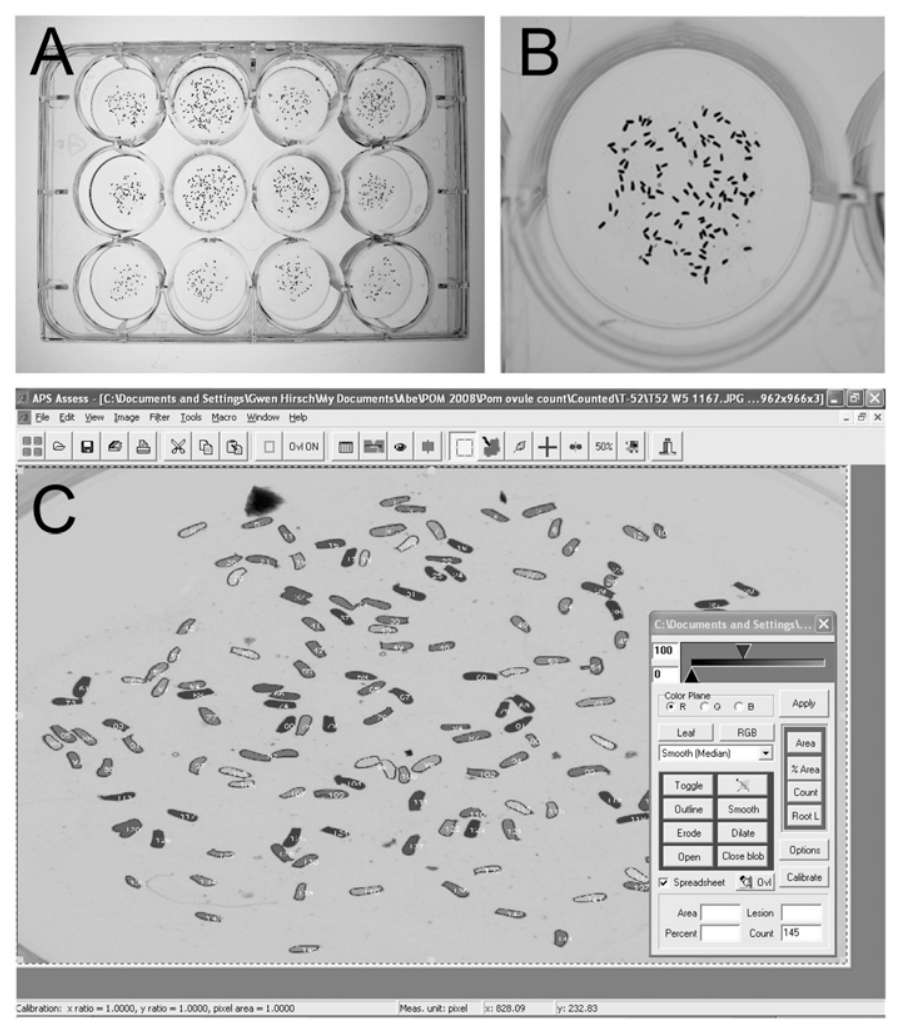

Fig. 3. Methods used to assess the number of ovules in individual pomegranate flowers. (A) Ovules were dissected and separated from placental and ovary tissues and then distributed into culture plate wells. (B) Image of an individual well containing ovules. (C) Screen showing image analysis program used to count the number of ovules in a well. In addition, each image was manually verified with corrections made for miscounting as a result of touching ovules (under counting) or counted cellular debris (overcounting).
FrUITSET AND SIZE STUDIES WITH CONTROLLED POLLINATIONS. Controlled pollinations of tagged flowers were made to assess the effects of flower size on subsequent fruit set and fruit size. Studies were made using 510 single-flower type flowers (Fig. 1A) that had opened on the same day. Flowers were tagged and numbered, and flower length (from the base of the ovary to the tip of sepals) and ovary width (at the widest area) were measured for each flower and recorded. Flowers were handpollinated using an artist paintbrush to apply fresh pollen collected from anthers that had just dehisced. Fruitset for each flower was assessed later in the season on 21 May and 6 July. Fruit that set from each of the tagged flowers was harvested at maturity, which corresponded to standard commercial maturity criteria and harvest time and then next-day shipped in coolers with blue ice to the University of Georgia for analysis. On arrival, whole fruit fresh weight, fruit width (as an average of two perpendicular measurements), and fruit height were measured. Fruit size data were related to original flower size at opening.

Statistical analysis. Statistical analyses were conducted using the General Linear Model (SAS Version 9.1; SAS Institute, Cary, NC). Flower measurements, ovule numbers, fruit set, and fruit weight were compared using Duncan's multiple range test at $\alpha=0.05$. Percent fruit set for flowers of different sizes was compared using $\chi^{2}$ analysis.

\section{Results}

Flower position AND SIZE MEasurements. Measurements of floral characteristics for the three flower types are summarized in Table 1, which shows mean values and ranges for each characteristic. Flower size in pomegranate can be quite variable. Within a flower type, characteristics exhibited a 1.5- to 2.8 -fold range in length from the smallest to largest flowers. Single and terminal flowers in a cluster had similar mean lengths for ovary width, flower length (from base to sepal notch and from base to sepal tip), and for different pistil length measurements. However, the largest flowers (those with the upper ranges) were in the terminal flower group. In contrast, lateral flowers in a cluster were significantly smaller than single and terminal flowers for all characteristics except stigma diameter. Furthermore, the largest flowers within that group were markedly smaller than in the other flower types, as shown by lower maximum size ranges for all characteristics except stigma diameter. Lateral flowers also had more variable pistil

Table 1. Length measurements for different floral characteristics in three bisexual flower types found in pomegranate: single flowers, terminal flowers within a flower cluster, and lateral flowers within a cluster.

\begin{tabular}{|c|c|c|c|c|c|c|}
\hline \multirow[b]{3}{*}{ Floral character ${ }^{z}$} & \multicolumn{6}{|c|}{ Flower type } \\
\hline & \multicolumn{2}{|c|}{ Single } & \multicolumn{2}{|c|}{ Terminal in a cluster } & \multicolumn{2}{|c|}{ Lateral in a cluster } \\
\hline & $\overline{\operatorname{Mean}^{\mathrm{y}}(\mathrm{mm})}$ & Range (mm) & Mean (mm) & Range (mm) & $\overline{\text { Mean }(\mathrm{mm})}$ & Range (mm) \\
\hline 1. Ovary width & $14.6 \mathrm{a}^{\mathrm{x}}$ & $11.7-18.2$ & $14.5 \mathrm{a}$ & $10.4-22.0$ & $13.6 \mathrm{~b}$ & $10.4-16.6$ \\
\hline 3. Base to sepal tip & $41.1 \mathrm{a}$ & $31.4-48.8$ & $42.0 \mathrm{a}$ & $31.3-50.8$ & $35.1 \mathrm{~b}$ & $25.0-46.2$ \\
\hline 4. Total pistil length & $31.2 \mathrm{a}$ & $23.2-37.1$ & $30.6 \mathrm{a}$ & $21.4-40.0$ & $26.1 \mathrm{~b}$ & $15.8-37.1$ \\
\hline 5. Stigma + style + stylopodium & $20.2 \mathrm{a}$ & $15.4-28.3$ & $20.1 \mathrm{a}$ & $15.7-31.5$ & $17.6 \mathrm{~b}$ & $8.6-23.3$ \\
\hline 7. Stigma diameter & $1.1 \mathrm{~b}$ & $0.3-1.6$ & $1.0 \mathrm{c}$ & $0.2-1.6$ & $1.3 \mathrm{a}$ & $0.8-1.8$ \\
\hline
\end{tabular}

${ }^{\mathrm{z}}$ Numbers correspond to flower characteristics diagrammed in Figure 2.

${ }^{\mathrm{y}}$ Means are from 100 flowers of each flower type.

${ }^{x}$ Means within a row followed by different letters are significantly different at $P \leq 0.05$ using Duncan's multiple range test. 
measurements (total pistil length, stigma length, and style plus stylopodium lengths) than other flower types. Total pistil length varied 2.3-fold in lateral flowers compared with 1.6- and 1.8-fold differences in single and terminal flowers, respectively. Lateral flowers had significantly shorter pistils, as indicated by the lower mean pistil length found in this flower type, which was $\approx 85 \%$ shorter than the other flower types (Table 1). In lateral flowers, pistil lengths ranged from 15.8 to $37.1 \mathrm{~mm}$. Thus, although flowers could be large, there were smaller flowers in this group compared with those in single flower (pistil lengths ranged from 23.2 to $37.1 \mathrm{~mm}$ ) and terminal flower (pistil lengths from 21.4 to $40.0 \mathrm{~mm}$ ) classes.

All flowers collected and measured were designated as being bisexual based on pistil and general ovary shape characteristics observed during field collection. Bisexual flowers have an elongated style and urn-shaped ovary in contrast to male flowers, which have shortened, underdeveloped pistils (Wetzstein et al., 2011a). However, on dissection of flowers in the laboratory, some were found to contain abortive ovule and placental tissues, the frequency of which varied with flower type. Although appearing typical of other bisexual flowers based on external morphology, $49 \%$ of lateral flowers had abortive internal ovary tissues, indicating that almost half of

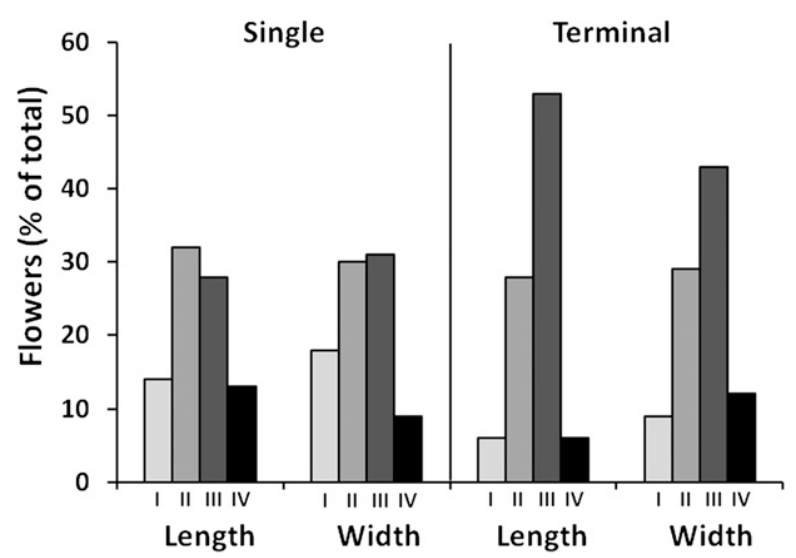

Fig. 4. Percentage of single and terminal pomegranate flowers types classified into different length or width size quartiles. Quartiles were derived by dividing the total range of flower widths (maximum ovary width) and lengths (distance from the ovary base to tip of sepals) into four size groups based on equal absolute length values with quartile I the smallest and quartile IV the largest. Data are for 100 flowers of each flower type. this flower type was incapable of setting fruit. In contrast, degeneration of internal tissues was relatively infrequent in single and terminal flower types; i.e., occurring in 10\% and $7 \%$ of flowers, respectively.

Flower size distributions for single and terminal flower types are shown in Figure 4. Flowers were categorized into four size groups that were derived by dividing the total range of flower lengths (distance from the ovary base to tip of sepals) and widths (maximum ovary width) into four size quartiles based on equal absolute length values. In single flower types, flower distribution patterns were similar whether flower size was based on length or width. The middle quartile groups (II and III) contained the most flowers with $\approx 30 \%$ of flowers falling into each of these middle quartiles. The smallest and largest size classes had fewer flowers but still collectively accounted for $\approx 27 \%$ of all flowers. Terminal flowers had a distribution pattern with the most flowers in quartile III, fewer in quartile II, and the least in quartiles I and IV; fewer flowers fit in into the more extreme quartiles. Distributions of terminal flowers based on length and width were similar; however, classification by width shifted distributions so there were fewer flowers in quartile III, which were reassigned into quartile IV.

Ovule number. Pomegranate flowers can contain large numbers of ovules, reaching to over 3000 ovules per flower in some cases (Table 2). Ovule numbers for single and terminal flower types are shown; ovules were not counted for lateral flowers because of the high frequency of degenerative ovary tissues observed in this type of flower. Ovule number varied widely with flower size, and significant differences were observed among size groups (Table 2). With single flower types categorized according to ovary width, the two largest flower groups (quartile III and IV) had significantly more ovules per flower than the two smaller groups (quartile I and II); none of the flowers in the smallest width class had developed ovules. When single flower types were categorized according to length, the largest flowers likewise had the greatest number of ovules. Significant differences in ovule numbers were found between the largest and smallest length quartiles; both quartiles I and II contained some flowers with no developed ovules. In terminal flowers within a cluster, larger flowers likewise had more ovules per flower; the two largest quartiles (III, IV) had significantly more ovules per flower than the two smallest quartiles (I and II) regardless of whether flower size was based on width or length characteristics. With both single and terminal flower types, all flowers lacking developed ovules were confined to the smallest size groups (Table 2). Nonetheless, flowers in the

Table 2. The relationship between flower size and the number of ovules per flower in pomegranate. ${ }^{z}$

\begin{tabular}{|c|c|c|c|c|c|c|c|c|}
\hline \multirow[b]{3}{*}{ Size quartile $^{\mathrm{y}}$} & \multicolumn{4}{|c|}{ Single flowers } & \multicolumn{4}{|c|}{ Terminal flowers of a cluster } \\
\hline & \multicolumn{2}{|c|}{ Width quartiles } & \multicolumn{2}{|c|}{ Length quartiles } & \multicolumn{2}{|c|}{ Width quartiles } & \multicolumn{2}{|c|}{ Length quartiles } \\
\hline & Ovules (no.) & Range & Ovules (no.) & Range & Ovules (no.) & Range & Ovules (no.) & Range \\
\hline $\mathrm{I}$ & $0 \mathrm{c}^{\mathrm{x}}$ & 0 & $1138 \mathrm{~b}$ & $0-1950$ & $394 \mathrm{~b}$ & $0-1968$ & $808 \mathrm{~b}$ & $0-2379$ \\
\hline III & $2253 \mathrm{a}$ & $1840-2544$ & $2204 \mathrm{ab}$ & $1990-2340$ & $2179 \mathrm{a}$ & $1659-3232$ & $2183 \mathrm{a}$ & $1809-2470$ \\
\hline IV & $2301 \mathrm{a}$ & $1950-2950$ & $2414 \mathrm{a}$ & $2032-2950$ & $2542 \mathrm{a}$ & 2269-2964 & $2807 \mathrm{a}$ & $1991-3238$ \\
\hline
\end{tabular}

${ }^{z}$ Two flower types (single flowers and terminal flowers within a flower cluster) were evaluated. The ovary of each flower was dissected open, and individual ovules were removed from placental tissues and plated into culture wells for counting using image analysis. Data are shown for flowers classified into size quartiles according to width and length.

${ }^{\mathrm{y}}$ Flowers were categorized into size quartiles derived by dividing the total range of flower widths (maximum ovary width) and lengths (distance from the ovary base to tip of sepals) into four groups based on equal absolute length values with quartile I the smallest and quartile IV the largest. ${ }^{x}$ Means within a column followed by different letters are significantly different at $P \leq 0.05$ using Duncan's multiple range test. 
smaller size groups varied widely and could contain fairly large numbers of ovules per flower: in single flowers, ovules per flower ranged from 0 to 2950 , and in terminal flowers, ovule numbers ranged from 0 to 3238 per flower. In contrast, flowers in larger size groups consistently had high numbers of ovules per flower. Single and terminal flowers in the two largest size groups all had over 1600 ovules per flower.

The disparity in ovule number distribution patterns among flowers of different size classifications is shown in box and whisker plots combining both flower types (Fig. 5). These plots show the median number of ovules, upper and lower medians (contained within boxes delimiting the 25th and 75th percentiles), and sample minimum and maximums for the different width and length size categories. The lower median numbers of ovules found in the smallest flowers (quartile I) are clearly evident. No developed ovules were found in flowers belonging to the smallest width quartile (Fig. 5A) with the exception of one outlier flower. Flowers within the next smallest width group (quartile II) had variable numbers of ovules ranging from those with no ovules to those containing relatively high numbers. When classified according to length (Fig. 5B), flowers in the two smaller size quartiles had ovule numbers that were very variable, ranging from those with no ovules to those with many ovules, i.e., ovule numbers for flowers within the 25 th to 75 th percentiles had between 0 and 1731 ovules in quartile I and 0 to 2288 ovules in quartile II. Thus, the smaller size classifications, whether defined by width or length, had flowers that either lacked ovules completely or had flowers of variable numbers of ovules (Fig. 5A-B). The wide range of ovule numbers found in smaller flowers was shown by their broad interquartile ranges. As flowers increased in size, ovule numbers were both higher and more consistent, exhibiting relatively little spread. All flowers in the two largest quartiles (regardless of whether size was based on width of length) had over 1600 ovules with lower median values of over 1956 ovules per flower (Fig. 5).

Fruitset AND FRUIT SIZE STUDiEs WITH HAND-POLlinated FLOWERS. To ascertain if flower size differences affect fruit size and production, studies were conducted where flowers whose length and width were measured were hand-pollinated and fruit set and fruit size subsequently assessed. Controlled pollinations were made using 510 single, bisexual flowers that had opened the day of pollination. Flowers exhibited a range in sizes. Flower widths ranged from 9.1 to $17.8 \mathrm{~mm}$, which was a 1.9-fold increase from smallest to largest. Flower lengths ranged from 33.7 to $53.4 \mathrm{~mm}$ long, which was a 1.6-fold increase from smallest to largest. The size distributions of flowers used for hand pollination are shown in Figure 6 with flowers divided into width and flower length quartiles based on absolute measured values. Flower size distributions were similar whether flowers were categorized by width or length. The highest frequency of flowers was found within size quartile III.

Percent fruit set was noticeably affected by flower size (Fig. 7). Flowers in the smallest size quartile had significantly lower fruit set than all other size groups; percent fruit set was only $12 \%$ or $20 \%$ depending on whether flowers were categorized by length or width, respectively. This is in sharp contrast

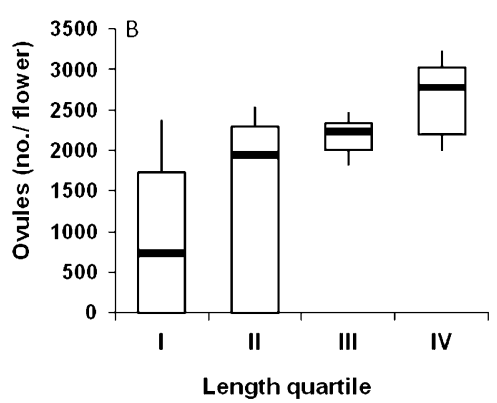

Width quartile

Length quartile

\section{(1)}

Fig. 5. Box and whisker plots showing the relationship between flower size and ovule number per flower in pomegranate. Flowers were classified according to flower width (maximum ovary width) number of ovules is shown, a box delineates the lower and upper medians, and whiskers indicate the . Data are for both terminal and single flowers with $n=53$ flowers.

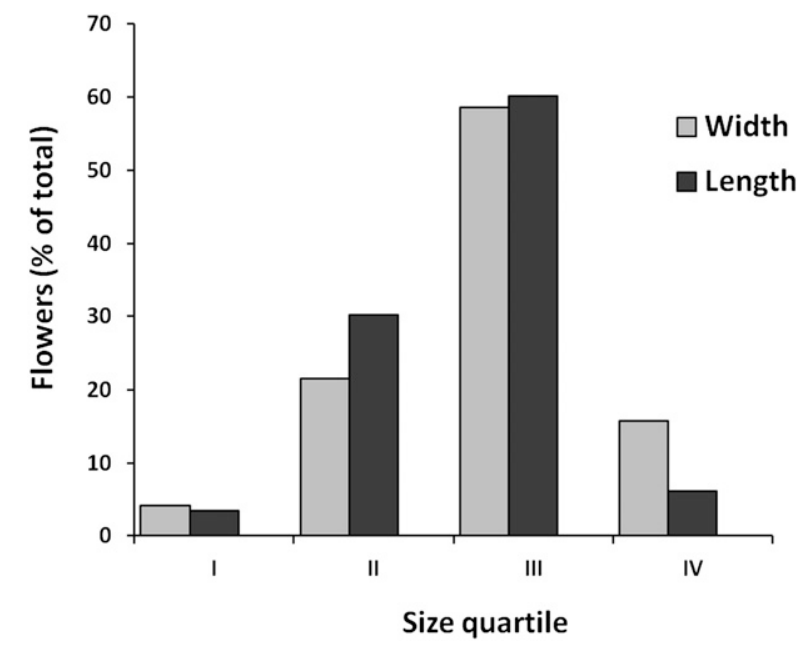

Fig. 6. Size distribution of pomegranate flowers used in hand pollination studies. Quartiles were derived by dividing the total range of flower widths (maximum ovary width) and lengths (distance from the ovary base to tip of sepals) of 510 randomly selected bisexual flowers into four size groups based on equal absolute length values with quartile I the smallest and quartile IV the largest.

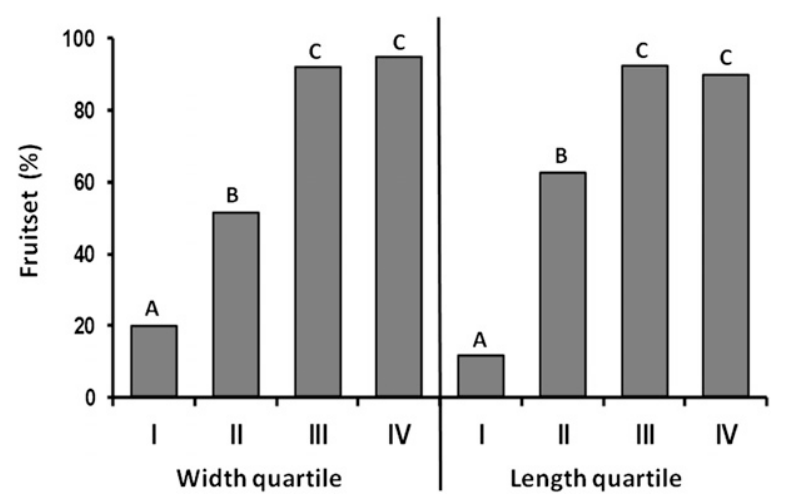

Fig. 7. Percent fruit set obtained in controlled pollinations of pomegranate flowers of different sizes. Data are for 510 single type flowers classified into different size quartiles derived by dividing the total range of flower widths (maximum ovary width) and lengths (distance from the ovary base to tip of sepals) into four size groups based on equal absolute length values with quartile I the smallest and quartile IV the largest. Mean separations are within width or length categories at $\alpha=0.01$ using $\chi^{2}$ analysis. 
to flowers in the largest size quartiles (III and IV), which had over $90 \%$ fruit set. Flowers in size quartile II had intermediate fruit set values of $51 \%$ and $62 \%$ for width and length classifications, respectively.

Flower size not only affected percent fruit set, but also had marked effects on the size of the fruit that set. Fruit size results for the fruit obtained in hand pollination studies are shown in Table 3. For each flower size quartile, mean fruit weight, number of fruit obtained, and percent of fruit in each fruit size category are summarized. Mean fruit weight significantly increased as flower size increased. Pollinated flowers categorized by ovary width produced significantly larger fruit as flower size increased. Flowers categorized by length likewise produced larger fruit as flower size increased with fruit in the largest quartile (IV) significantly larger than that obtained with flowers in quartile II. Summary data for fruit obtained with the smallest flowers (quartile I) are not shown as a result of the low fruit set and few fruit obtained in pollinations with this flower size; only four or two fruit were obtained in flowers categorized by width and length, respectively. The fruit obtained from hand pollinations exhibited wide ranges in size. Fruit size categories, which correspond to commercial packing sizes, ranged from undersize fruit (less than $71 \mathrm{~mm}$ diameter) to Size 16 fruit (116 to $126 \mathrm{~mm}$ diameter); smaller size numbers reflect larger fruit. As flower size increased, the percentages of fruit in larger size categories likewise increased. Approximately 95\% of fruit obtained from pollinating quartile IV flowers were Size 30 or larger in contrast to $76 \%$ of fruit of those sizes obtained from pollinating size III flowers and $58 \%$ of fruit from Size II flowers. When flowers were classified by length, higher numbers of larger fruit were likewise obtained, although differences among flower size groups were less distinct.

Table 3. Characteristics of fruit obtained from controlled pollinations of pomegranate flowers of different sizes. ${ }^{\mathrm{z}}$

\begin{tabular}{|c|c|c|c|c|c|c|c|c|c|}
\hline \multirow[b]{2}{*}{$\begin{array}{l}\text { Size } \\
\text { quartile }^{y}\end{array}$} & \multirow{2}{*}{$\begin{array}{l}\text { Mean } \\
\text { fruit } \\
\text { wt }(\mathrm{g})\end{array}$} & \multirow[b]{2}{*}{$\begin{array}{l}\text { Fruit } \\
\text { (no.) }\end{array}$} & \multicolumn{7}{|c|}{ Fruit in each size category $(\%)^{x}$} \\
\hline & & & $\begin{array}{l}\text { Size } \\
\text { US }\end{array}$ & $\begin{array}{c}\text { Size } \\
42\end{array}$ & $\begin{array}{c}\text { Size } \\
36\end{array}$ & $\begin{array}{c}\text { Size } \\
30\end{array}$ & $\begin{array}{c}\text { Size } \\
22\end{array}$ & $\begin{array}{c}\text { Size } \\
16\end{array}$ & $\begin{array}{c}\text { Size }^{\mathrm{w}} 30 \\
\text { or less }\end{array}$ \\
\hline \multicolumn{10}{|l|}{ Width } \\
\hline $\mathrm{I}^{\mathrm{v}}$ & - & 4 & - & - & - & - & - & - & - \\
\hline II & $387 \mathrm{c}^{\mathrm{u}}$ & 48 & 0 & 4.2 & 37.5 & 43.8 & 14.6 & 0 & 58.4 \\
\hline III & $435 \mathrm{~b}$ & 223 & 1.4 & 2.2 & 20.6 & 33.2 & 42.2 & 0.5 & 75.9 \\
\hline IV & $497 \mathrm{a}$ & 58 & 0 & 0 & 5.2 & 36.2 & 53.5 & 5.2 & 94.9 \\
\hline \multicolumn{10}{|l|}{ Length } \\
\hline I & - & 2 & - & - & - & - & - & - & - \\
\hline II & $410 \mathrm{~b}$ & 79 & 2.5 & 3.8 & 25.3 & 34.2 & 32.9 & 1.3 & 68.4 \\
\hline III & $445 \mathrm{ab}$ & 231 & 0.4 & 1.7 & 19.5 & 35.5 & 41.6 & 1.3 & 78.4 \\
\hline IV & $473 \mathrm{a}$ & 21 & 0 & 4.8 & 14.3 & 33.3 & 47.6 & 0 & 80.9 \\
\hline
\end{tabular}

${ }^{\mathrm{z}}$ Data are for flowers classified into size quartiles according to width and length.

${ }^{y}$ Flowers were categorized into size quartiles derived by dividing the total range of flower widths (maximum ovary width) and lengths (distance from the ovary base to tip of sepals) into four groups based on equal absolute length values with quartile I the smallest and quartile IV the largest.

${ }^{\mathrm{x}}$ Fruit size categories refer to commercial packing sizes. Smaller numbers reflect larger fruit. US refers to undersize fruit.

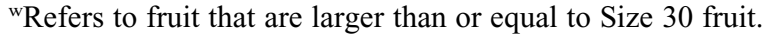

${ }^{\mathrm{v}}$ Size data are not reported for quartile I as a result of the low percent fruit set and few fruit obtained.

"Means within a column followed by different letters are significantly different at $P \leq 0.05$ using Duncan's multiple range test.

\section{Discussion}

Pomegranate trees characteristically produce large numbers of flowers that are either bisexual types capable of setting fruit or functionally male flower types, which characteristically abort (Shulman et al., 1984; Wetzstein et al., 2011a). The current study verifies that in addition to the general flower gender classifications, a wide gradient of flower quality exists within bisexual flower types with marked differences in floral characteristics observed, which subsequently influence fruit production and fruit size. The three bisexual flower types evaluated in this study (single, terminal, lateral) had pistil size characteristics (i.e., total pistil length and stigma/style/stylopodium lengths) that varied markedly from 2.5- to 3.7-fold and had length and ovary widths that varied over 2-fold. Furthermore, this study documents that flower size characteristics and ovule development are related to flower type and position. Single and terminal flowers within a cluster were larger than lateral flowers. In addition, lateral flowers exhibited a high frequency of flowers with poor ovule development sufficient to negatively impact fruiting in that flower type. Pollination studies verified that fruit set and final fruit size were impacted by flower size at the time of pollination. Percent fruit set was clearly higher with larger flowers, in which over $95 \%$ fruit set was obtained in the two largest size quartiles. This was in contrast to the smallest flowers in which set was less than $20 \%$. Furthermore, among the fruit that set, mean fruit weight significantly increased as flower size increased, and larger commercial fruit size distributions were obtained with larger vs. smaller flowers. This study thus clearly verifies that flower quality impacts fruit production and size.

Unfruitfulness and poor seed development in flowering plants can be a consequence of a number of factors including insufficient maternal resources (i.e., carbon allocation, nutrition, flower quality), flower age effects on receptivity, and inadequate pollen delivery (i.e., lack of pollinators, inviable pollen, sexual incompatibility). In the current study, the experimental system was controlled so that flowers of the same age and type were uniformly hand-pollinated on the same date, grown under identical orchard management conditions, and harvested at the same age. The effects of flower size could be clearly evaluated in that flower receptivity, pollen load, pollen viability, and fruit maturity were standardized.

Because size is an important quality attribute in fruit crops, considerable work has been conducted to assess the underlying causes influencing fruit size. Larger fruit were associated with greater numbers of mesocarp cells in peach (Scorza et al., 1991), sweet cherry [Prunus avium (Olmstead et al., 2007)], rabbiteye blueberry (Johnson et al., 2011), and olive (Rapoport et al., 2004). In mandarin (Citrus aurantium), larger fruit size was attributed to enhanced cell elongation in juice sac cells (El-Otmani et al., 1993). In apple, both greater cell division and enhanced cell elongation in perianth tissues were associated with large-sized fruit (Harada et al., 2005). Notably different is that in pomegranate, the edible portion and underlying tissues that contribute to final fruit size are not derived from the ovary wall, pericarp tissues, or flower receptacle. Instead, the edible arils and juice sacs are derived from ovule/seed-related tissues. This condition prompted the assessment of ovule numbers in the present study. The number of functional ovules in a flower at anthesis is a key consideration because it may potentially influence aril number and thus fruit size in pomegranate. The 
current study shows that ovule numbers per flower were significantly influenced by flower size with more ovules found in larger flowers. Flower size is likely to spatially and developmentally impact ovular tissue differentiation.

Flower type and position strongly affected flower quality. Single flowers and terminal flowers within clusters were larger and contained more ovules than lateral flowers within a cluster. Almost half of the lateral flowers had abortive ovules on dissection and were thus incapable of setting fruit. Flower size and position have been shown to influence production in other fruit crops. In apple, king flowers (also the terminal flower in a cluster) consistently have higher fruit set than lateral flowers, which has been suggested to occur because king flowers form earlier, are larger in size, and have better vascular connections than lateral flowers (Dennis, 1986). King flowers are reported to have greater sink strength and greater numbers of cells (Westwood et al., 1967). Similarly, Prunus mahaleb fruit set varied with flower position with most fruit produced from flowers that were the first to open (Guitian, 1994). Early flowers were proposed to have advantages in terms of embryo development, sink establishment, and resource capture.

In pomegranate, lateral flower development is delayed compared with terminal flowers. The lateral flowers evaluated in the current study were within flower clusters containing developing terminal fruitlets. Unclear is whether the earlier opening and pollination of terminal flowers impact subsequent lateral flower differentiation and contribute to the lack of developed ovules frequently observed in lateral flowers. The presence of developing fruit can have an inhibitory effect on fruit set and growth of later fruit. Developing fruit and seed have long been known to influence development through changes in hormonal activity and synthesis (Leopold and Kriedemann, 1975; Marcelis and Baan Hofman-eijer, 1997). The activity of reproductive meristems is regulated by factors such as transcriptional regulators, plant hormones, and reserve accumulation (Bartrina et al., 2011; Reale et al., 2009; Zhou et al., 2012). The development of functional hermaphroditic flowers was correlated with adequate starch content (Reale et al., 2009). A temporal assessment of ovule development has not been documented in pomegranate. Future experiments that incorporate histological studies of lateral flowers in conjunction with the influence of terminal flower thinning would provide information on the timing and plasticity of lateral flower development. Likewise, the differences in ovule numbers observed in flowers categorized into larger and smaller size classes may be the consequence of similar underlying differences in sink strength and hormonal activity.

In the current study, flowers in the smallest size category (quartile I) had extremely low (20\% or less) fruit set, the next largest size (quartile II) had intermediate fruit set (51\% to 62\%), and the two largest size categories (quartiles III, IV) had $90 \%$ or greater fruit set. In fruit containing numerous seed, fruit set may be influenced by the number of developing seeds within a fruit, which theoretically may need to reach a threshold number for fruit retention. This appears to be the case with pomegranate in that larger flowers had similarly high percent fruit set (Fig. 7) but exhibited an increase in mean fruit weight with increasing flower size (Table 3). In Capsicum annuum, fruit set was affected by seed number up to a limit (Marcelis and Baan Hofman-eijer, 1997). When seed numbers were low, fruit set was positively related to seed number. However, beyond $20 \%$ to $30 \%$ of maximum seed number, fruit set was maximal.
Problems in ovule development have been shown to impact fruit production in a number of other species. Lack of fruit set has been attributed to immaturity of the embryo sac, ovule degeneration, and/or lack of synchronization between the female gametophyte and pollen tubes in japanese plum [Prunus salicina (Guerra et al., 2011)], apricot [Prunus armeniaca (Alburquerque et al., 2004)], avocado [Persea americana (Tomer et al., 1976)], litchi [Litchi chinensis (Stern et al., 1996)], and sour cherry [Prunus cerasus (Cerovic and Micic, 1999)]. In apple, the coincidence of greater numbers of seed and higher fruit set found with terminal vs. lateral blossoms suggests there may be innate differences in ovule viability between the flower types (Weinbaum and Simons, 1976). Ovule development in Prunus species displaying premature drop exhibited abnormal characteristics such as degeneration of ovules and callose deposition that were apparent already in the bud stage of flowers (Dittmann and Stosser, 1999).

In pomegranate, having viable, well-developed ovules at the time of pollen tube growth is a prerequisite to the formation of arils in the mature fruit. Fruit size in pomegranate is clearly related to the number of arils within a fruit (Wetzstein et al., $2011 \mathrm{~b}$ ). The lack of developed ovules commonly observed in lateral flowers and in smaller single and terminal flowers may limit fruit production in those flowers. Nevertheless, a flower containing large numbers of ovules does not necessarily indicate that fruit derived from such a flower will set or be large. Rather, ovule number indicates the reproductive potential of a particular flower. It should be noted that although flowers could have as many as 3200 ovules in a single flower, the largest fruit for the 'Wonderful' genotype characteristically contain $\approx 1000$ arils (Wetzstein et al., 2011b). This indicates that many flowers contain ovules that do not develop into mature arils signifying that ovule number per se is not the sole factor, and that other features play an important role. Unclear is the proportion of ovules that are functional during the time that pollination occurs; i.e., having a differentiated embryo sac that is capable of fertilization and subsequent development into a mature embryo/ aril. Differences in ovule quality and longevity among flowers of diverse sizes and positions are possible. Evaluations of ovule anatomy using histological methods were not conducted to compare flowers of different sizes. Furthermore, the number of pollen tubes that germinate on the stigma and that can be supported to grow down the style may be further limitations to fertilization and aril development.

Larger flowers may reflect an overall increase in vigor of not only the ovary and number of ovules per flower, but also of stigma and style tissues. Functionally male flowers in pomegranate not only have rudimentary ovules, but also are characterized as having little stigmatic exudate, pollen tubes that exhibit disoriented growth on the stigma, shortened styles, and few or no pollen tubes growing within the stylar canal (Wetzstein et al., 2011a). Pistil quality could influence pollen germination, tube growth, and fertilization, which ultimately would affect aril number and fruit size. Larger fruit obtained with larger flowers, as indicated by higher percentages of fruits that sized into the larger commercial packing sizes, may reflect such overall flower vigor effects. Production of large fruit requires adequate pollen deposition on a receptive stigma, pollen tube growth within the style, and fertilization of hundreds of ovules. Pistil traits were found to influence fruit set in apricot (Rodrigo et al., 2009). Under similar pollination conditions, flowers that set fruit had a larger stigmatic area, supported 
higher numbers of pollen tubes growing along the style, and contained more xylem vessels and starch in transmitting tissue compared with flowers that abscised.

In pomegranate, flower size can be used as an indication of flower quality. Flowers in the larger size groups were more consistent in having high numbers of well-developed ovules in contrast to smaller flowers whose distribution and range of ovule numbers was exceptionally wide and included flowers with no developed ovules. Furthermore, flower performance was superior with larger vs. smaller flowers; larger flowers had significantly higher fruit set, greater final fruit weight, and more fruit in larger commercial size categories. Thus, flower quality is an important issue in pomegranate, and cultural and environmental factors that influence flower size and vigor may have a direct consequence on fruit production and yield. In some years, low numbers of female flowers limit yield. The percentage of flowers that are male in pomegranate can be significant and more than $60 \%$ to $70 \%$ depending on variety and season (Chaudhari and Desai, 1993; Mars, 2000). Cultural practices including nitrogen fertilization, pruning, cropload, time of harvest, and rainfall/irrigation can influence flower quality and fruit setting ability in fruit crops. Incorporating cultural practices that promote the development of flowers with high vigor may have merit. Enhancing the production of larger and stronger flowers may be a means to improve yield, particularly in a species such as pomegranate in which sex expression and presumably flower strength appear to be labile.

\section{Literature Cited}

Alburquerque, N., L. Burgos, M. Sedgley, and J. Egea. 2004. Contributing to the knowledge of the fertilization process in four apricot cultivars. Sci. Hort. 102:387-396.

Bartrina, I., E. Otto, M. Strnad, T. Werner, and T. Schmulling. 2011. Cytokinin regulates the activity of reproductive meristems, flower organ size, ovule formation, and thus seed yield in Arabidopsis thalliana. Amer. J. Bot. 96:1159-1167.

Basu, A. and K. Penugonda. 2008. Pomegranate juice: A heart healthy fruit juice. Nutr. Rev. 67:49-56.

Cerovic, R. and N. Micic. 1999. Functionality of embryo sac as related to their variability and fertilization success in sour cherry. Sci. Hort. 79:227-235.

Chaudhari, S.M. and U.T. Desai. 1993. Effects of plant growth regulators on flower sex in pomegranate (Punica granatum L). Indian J. Agr. Sci. 63:34-35.

Dennis, F.G. 1986. Apple, p. 1-44. In: Monselise, S.P. (ed.). Handbook of fruit set and development. CRC Press, Boca Raton, FL.

Dittmann, K. and R. Stosser. 1999. Development of ovules in relation to premature fruit drop in Prunus species. J. Appl. Bot. Angewandte Botanik 73:86-98.

El-Otmani, M., M. Agusti, M. Aznar, and V. Almela. 1993. Improving the size of 'Fortune' mandarin fruits by the auxin 2, 4-DP. Sci. Hort. 55:283-290.

Guerra, M.E., A. Wunsch, M. Lopez-Corrales, and J. Rodrigo. 2011. Lack of fruit set caused by ovule degeneration in japanese plum. J. Amer. Soc. Hort. Sci. 136:10-15.

Guitian, J. 1994. Selective fruit abortion in Prunus mahaleb (Rosaceae). Amer. J. Bot. 81:1555-1558.
Harada, T., W. Kurahashi, M. Yanai, Y. Wakasa, and T. Satoh. 2005. Involvement of cell proliferation and cell enlargement in increasing the fruit size of Malus species. Sci. Hort. 105:447-456.

Holland, D., K. Hatib, and I. Bar-Ya'akov. 2009. Pomegranate: Botany, horticulture, breeding. Hort. Rev. 35:127-191.

Johnson, K.L., A. Malladi, and D.S. NeSmith. 2011. Differences in cell number facilitate fruit size variation in rabbiteye blueberry genotypes. J. Amer. Soc. Hort. Sci. 136:10-15.

Lansky, E.P. and R.A. Newman. 2007. Punica granatum (pomegranate) and its potential for prevention and treatment of inflammation and cancer. J. Ethnopharmacol. 109:177-206.

Leopold, A.C. and P.E. Kriedemann. 1975. Plant growth and development. McGraw-Hill, New York, NY.

Marcelis, L.F.M. and L.R. Baan Hofman-eijer. 1997. Effects of seed number on competition and dominance among fruits in Capsicum annuum L. Ann. Bot. (Lond.) 79:687-693.

Mars, M. 2000. Pomegranate plant material: Genetic resources and breeding, A review. Options Mediterraneennes Serie A 42:55-62.

Olmstead, J.W., A.F. Iezzoni, and M.D. Whiting. 2007. Genotypic differences in sweet cherry fruit size are primarily a function of cell number. J. Amer. Soc. Hort. Sci. 136:10-15.

Rapoport, H.F., T. Manrique, and R. Cucci. 2004. Cell division and expansion in the olive. Acta Hort. 636:461-465.

Reale, L., C. Sgromo, L. Ederli, S. Pasqualini, F. Orlandi, M. Fornaciari, F. Ferranti, and B. Romano. 2009. Morphological and cytological development and starch accumulation in hermaphrodite and staminate flowers of olive (Olea europa L.). Sex. Plant Reprod. 22: 109-119.

Rodrigo, J., M. Herrero, and J.I. Hormaza. 2009. Pistil traits and flower fate in apricot (Prunus armeniaca). Ann. Appl. Biol. 154:365-375.

Rosati, A., M. Zipancic, S. Caporali, and G. Padula. 2009. Fruit weight is related to ovary weight in olive (Olea europaea L.). Sci. Hort. 122:399-403.

Scorza, R., L.G. May, B. Purnell, and B. Upchurch. 1991. Differences in number and area of mesocarp cells between small- and largefruited peach cultivars. J. Amer. Soc. Hort. Sci. 116:861-864.

Seeram, N.P., R.N. Schulman, and D. Heber. 2006. Pomegranates: Ancient roots to modern medicine. CRC Press, Boca Raton, FL.

Shulman, Y., L. Fainberestein, and S. Lavee. 1984. Pomegranate fruit development and maturation. J. Hort. Sci. 59:265-274.

Stern, R.A., D. Eisenstein, H. Voet, and S. Gazit. 1996. Anatomical structure of two day old litchi ovules in relation to fruit set and yield. J. Hort. Sci. 71:661-671.

Tomer, E., M. Gottreich, and S. Gazit. 1976. Defective ovules in avocado cultivars. J. Amer. Soc. Hort. Sci. 101:620-623.

Weinbaum, S.A. and R.K. Simons. 1976. Relationship of seed number to fruit set in apple. Fruit Var. J. 30:82-84.

Westwood, M.N., L.P. Batjer, and H.D. Billings. 1967. Cell size, cell number and fruit density of apples as related to fruit size, position in the cluster, and thinning method. Proc. Amer. Soc. Hort. Sci. 91:51-62.

Wetzstein, H.Y., N. Ravid, E. Wilkins, and A.P. Martinelli. 2011a. A morphological and histological characterization of bisexual and male flower types in pomegranate. J. Amer. Soc. Hort. Sci. 136:83-92. Wetzstein, H.Y., Z. Zhang, N. Ravid, E. Wilkins, and M.E. Wetzstein. 2011 b. Characterization of attributes related to fruit size in pomegranate. HortScience 46:908-912.

Zhou, Y., S. Gao, X. Zhang, H. Gao, Q. Hu, Y. Song, Y. Jiao, and H. Gao. 2012. Morphology and biochemical characteristics of pistils in the staminate flowers of yellow horn during selective abortion. Aust. J. Bot. 60:143-153. 